\title{
Prevalence of Depression among Chinese University Students: A Meta-Analysis
}

\author{
Xian-Yang Lei ${ }^{1,2}$, La-Mei Xiao', Ya-Nan Liư ${ }^{3}$, Ya-Min Li ${ }^{1}$ * \\ 1 The Second Xiangya Hospital, Central South University, Changsha, Hunan Province, China, 2 Office of \\ the President, Central South University, Changsha, Hunan Province, China, 3 Xiangya Nursing School, \\ Central South University, Changsha, Hunan Province, China \\ * li_yamin3@163.com
}

\section{Abstract}

\section{Background}

Depression is a major mental health issue worldwide, and university students with heavy burdens of study are at a high risk for depression. While a number of studies have been conducted regarding depression among university students in China, there is a lack of information regarding the national prevalence of depression among Chinese university students. Therefore, we performed a meta-analysis to statistically pool the prevalence of depression among Chinese university students.

\section{Methods}

open AcCess

Citation: Lei X-Y, Xiao L-M, Liu Y-N, Li Y-M (2016) Prevalence of Depression among Chinese University Students: A Meta-Analysis. PLoS ONE 11(4): e0153454. doi:10.1371/journal.pone.0153454

Editor: Jakob Pietschnig, Universitat Wien, AUSTRIA

Received: October 19, 2015

Accepted: March 30, 2016

Published: April 12, 2016

Copyright: @ 2016 Lei et al. This is an open access article distributed under the terms of the Creative Commons Attribution License, which permits unrestricted use, distribution, and reproduction in any medium, provided the original author and source are credited.

Data Availability Statement: All relevant data are within the paper and its Supporting Information files.

Funding: The authors received no specific funding for this work.

Competing Interests: The authors have declared that no competing interests exist.
A systematic search of scientific databases was conducted, including Chinese Web of Knowledge, Embase, PubMed, Wanfang (a Chinese database) and Weipu (a Chinese database) to find relevant publications published between 1995 and December 2015. This was supplemented by a secondary review of the reference lists of all retrieved papers to find additional relevant citations. Studies published in either English or Chinese that provided prevalence estimates of depression in Chinese university students were considered. Prevalence estimates of each eligible study were extracted and pooled in our meta-analysis using a random-effects model.

\section{Results}

A total of 39 studies conducted between 1997 and 2015 including 32,694 university students were analyzed. Our results indicate that the overall prevalence of depression among Chinese university students is $23.8 \%(95 \% \mathrm{Cl}$ : $19.9 \%-28.5 \%)$. Substantial heterogeneity in prevalence estimates was noted. Subgroup analysis revealed that the prevalence of depression among medical students is higher than among other students.

\section{Conclusions}

Overall, the prevalence of depression among Chinese university students is exceedingly high. This suggests that it is imperative that more attention be given to the development of appropriate mental healthcare strategies for university students in China. 


\section{Introduction}

Depressive disorder is one of the most common mental health disorders, and the prevalence of the disease reflects the mental health of the population. Depression is a worldwide problem with a lifetime prevalence of $16.2 \%$ and a 1 -year prevalence of $6.6 \%$ among the general population [1]. Depression creates a heavy burden on society as a multi-problematic disorder that leads to impairment in interpersonal, occupational, and social functioning [2-4]. University students are in a special period of life in which they grow from adolescence to adulthood and consequently make many important life decisions. During this crucial stage, university students experience enormous pressure, mostly from economic stress, academic demands, and interpersonal relationships [5]. Research indicates that mental health among university students is poorer compared to their peers around the world, with high rates of mental disorders such as depression and anxiety [6-9]. For many university students, depression can not only induce terrible feelings, such as fright, feelings of inadequacy, and anger, but it also can be connected with psychological and physical morbidities [10-11]. Previous studies have reported that depression in university students is prevalent in many countries [5, 10-14], and the prevalence appears to be increasing. Moreover, depression is associated with several severe problems in university students, notably suicidal ideation [15-16], substance abuse [17-18], and acute infectious illnesses [19]. As a result, depression among university students is a major problem, highlighting the need to explore factors that are associated with depression and to provide appropriate interventions to mitigate these factors among university students.

In China, most current university students were born after the "one-child" policy changed from an incentive-based policy to a mandatory one. The majority of undergraduates today are from single-child families [20]. Consequently, some argue that this generation of children exhibits greater recklessness and an inadequate ability to endure negative life events compared to their peers with siblings [21].

It is acknowledged that the southern region of mainland China has a better economic status and medical health care than the north region. However, whether university students in south region of mainland China are less likely to be depressed remains uncertain. Besides, the enrollment expansion in Chinese university started about in 2000 has caused inadequate employment opportunities for graduates, which may potentially increase stress and pressure in obtaining employment.

Although there is a growing number of research investigating the prevalence of depression among university students, little is known about the quantitative syntheses of overall prevalence in China. And cross-countries comparison demonstrated that Asians are less likely to report their depression than people in western countries [22], and thus lower rates of depression had been reported in Chinese university students. Primary prevention is the best and most effective strategy for depression, but it requires a careful plan of action in order to adequately improve current policies regarding depression among university students. Hence, we performed a meta-analysis that summarizes the prevalence of depression among Chinese university students in order to help develop future research priorities. Moreover, the differences of prevalence of depression on sex (male and female), region (North and South) and study period (stratified by years) were also analyzed.

\section{Materials and Methods}

\section{Search strategy}

A systematic literature search was conducted using Chinese Web of Knowledge, Embase, PubMed, Wanfang (a Chinese database), and Weipu (a Chinese database) to find studies that 
reported the prevalence of depression among Chinese university students and published between 1995 to December 2015. Articles published in either English or Chinese were considered. The following search terms were used to find relevant articles: ('depression OR depress* OR mood OR mental OR affective) AND ('college student' OR 'university student' OR 'undergraduate'). In addition, a secondary search was performed by reviewing the reference lists of identified papers that were potentially eligible for inclusion according to our eligibility criteria. The screening process examined titles, abstracts, and full-text of potential articles and was conducted by two authors to ensure all eligible articles were included.

\section{Eligibility criterion}

Studies were included if they met the following eligibility criteria: 1) the study was an original epidemiological study conducted among Chinese university students; 2) the study used screening methods and/or screening tools to diagnose depression and provided a description of these screening methods; 3 ) the study provided a prevalence estimation (or raw data that could be used to calculate the prevalence) of depression among Chinese university students; and 4) the study was published in English or Chinese and in the past 20 years. Two authors, one of whom was designated the primary author, investigated publications independently, and any discrepancies were resolved by the primary author

\section{Data extraction}

Relevant information from the included studies was independently extracted by two reviewers. When there was a disagreement regarding whether a study should be included for analysis, the primary author made the final decision. The following information was extracted from each eligible study: first author name, year of publication, province of China, area of China (southern or northern), number of students with depression and total sample size, percentage of male subjects, prevalence estimation, sex-specific prevalence (if available), student major (i.e., medical student or other) and grade level, and screening methods for depression.

\section{Statistical analysis}

The estimates of prevalence extracted from studies were first transformed into a quantity using the Freeman-Tukey variant of the arcsine square root transformed proportion [23], which is suitable for both the fixed and random effects summaries [24]. This was performed because the weight of inverse variance in meta-analyses with fixed-effects models is not optimal when dealing with binary data with low proportion. Additionally, this method is useful because it allows studies that reported a prevalence of 0 to also be included in the meta-analysis since the transformed estimates of prevalence are weighted very slightly towards $50 \%$ [21].

The pooled proportion was calculated using the back-transformation of the weighted mean of the transformed proportions, using inverse arcsine variance weights for the fixed-effects model and DerSimonian-Laird weights for the random-effects model. Heterogeneity across studies was evaluated with the $\mathrm{I}^{2}$ statistic, which can show the variation between studies with a percentage. Heterogeneities of $25 \%, 50 \%$, and $75 \%$ were considered as low-, moderate-, and high-level heterogeneity, respectively [25]. For studies with high heterogeneity, the DerSimonian and Laird random-effect model was used to calculate the summary prevalence [26]. In order to explore heterogeneity across studies, subgroup analysis was performed to determine whether there were significant differences between the subgroups. Subgroups were defined on the basis of difference in study year, sample size, area of China, student major, and sex. To enlarge the pooled sample size and examine the sex differences, a subgroup analysis of percentage of male subjects was conducted as well. Besides, sensitivity analysis was performed to test 
the robustness of the pooled prevalence of depression by excluding each study and rerunning the meta-analysis. Finally, publication bias was assessed using the Egger's or Begg's regression model [27] and a visual inspection of a funnel plot. All statistical calculations were made using Stata (version 12.0; Stata Corporation, College Station, Texas, USA).

\section{Results}

\section{Study selection and characteristics}

A total of 1855 records were collected during the initial search, and after removal of duplicates, 1292 studies were screened by title and abstract. No new studies were retrieved during the secondary search that reviewed the bibliographies of the full-text papers collected during the initial search. In total, 39 studies, comprising 32,694 university students, were identified and included after exclusion of ineligible reports. A detailed flow chart of the search and selection process is presented in Fig 1. Table 1 presents the baseline characteristics of the 39 studies included in this analysis [28-34] (references for the 32 studies published in Chinese are presented in S1 Text). Of the 39 studies, 22 were conducted in North China and 17 were conducted in South China. In regards to type of students studied, 11 of the 39 studies targeted on medical students and 28 focused on both medical and non-medical students. The sample size of the included studies ranged from 176 to 3744 . Most studies assessed the presence of depression using the Self-rating Depression Scale (SDS) [35], but several other methods were applied as well: four used the Beck Depression Inventory (BDI) [36], one used the Depression Status Inventory (DSI) [37], three used the Hamilton Depression Scale (HAMD) [38], one used Depressive Experiences Questionnaire (DEQ) [39], two used the Chinese version of the Center for Epidemiological Survey, Depression Scale (CES-D) [40], one used the Chinese version of Patient Health Questionnaire (PHQ-9) [41] and one used the revised Hopkins Symptom Checklist (SCL-90-R) [42].

\section{Prevalence}

The reported prevalence of depression among the 39 individual study populations ranged from $3.0 \%$ to $80.6 \%$, with a pooled prevalence of $23.8 \%$ (95\% CI: $19.9 \%-28.5 \%$, Fig 2 ), and there was evidence of substantial heterogeneity across the studies $\left(\mathrm{I}^{2}=99.4 \%, \mathrm{P}<0.001\right)$.

\section{Subgroup analyses}

The pooled prevalence of depression among all subgroups according to study year, sex, percentage of male subjects, student major, area of China, sample size and screening method are summarized in Table 2. The pooled estimates of depression decreased over time. Between 1995 and 2000 , the pooled prevalence was $27.8 \%$ (95\% CI: $11.1 \%-69.6 \%$ ), the estimate of depression was $24.0 \%$ (95\% CI: $16.1 \%-35.8 \%$ ) in studies conducted from 2001 to 2005 , and $25.2 \%$ (95\% CI: $18.2 \%-34.7 \%$ ) in studies conducted from 2006 to 2010 . However, the estimate was $21.9 \%$ in studies conducted during 2011-2015 (95\% CI: 16.2\%-29.6\%), which represents a remarkable decline in depression. According to the subgroup of sex, the prevalence of depression among males (30.0\%, 95\% CI: 14.9\%-60.2\%) was a little higher than the prevalence of depression among females (27.1\%, 95\% CI: $13.2 \%-55.5 \%)$. However, the prevalence estimates in studies with samples that included fewer than $50 \%$ male subjects $(24.1 \%, 95 \%$ CI: $18.6 \%-31.2 \%)$ were higher than estimates in studies with more than $50 \%$ male subjects (22.3\%, 95\% CI: $16.4 \%-$ $30.2 \%)$. As a result, there was no significant difference between estimates of depression between males and females. The prevalence of depression among non-medical students (22.4\%, 95\% CI: $17.9 \%-28.1 \%)$ was lower than among medical students (27.5\%, 95\% CI: $19.8 \%-38.3 \%$ ). 


\section{PRISMA 2009 Flow Diagram}
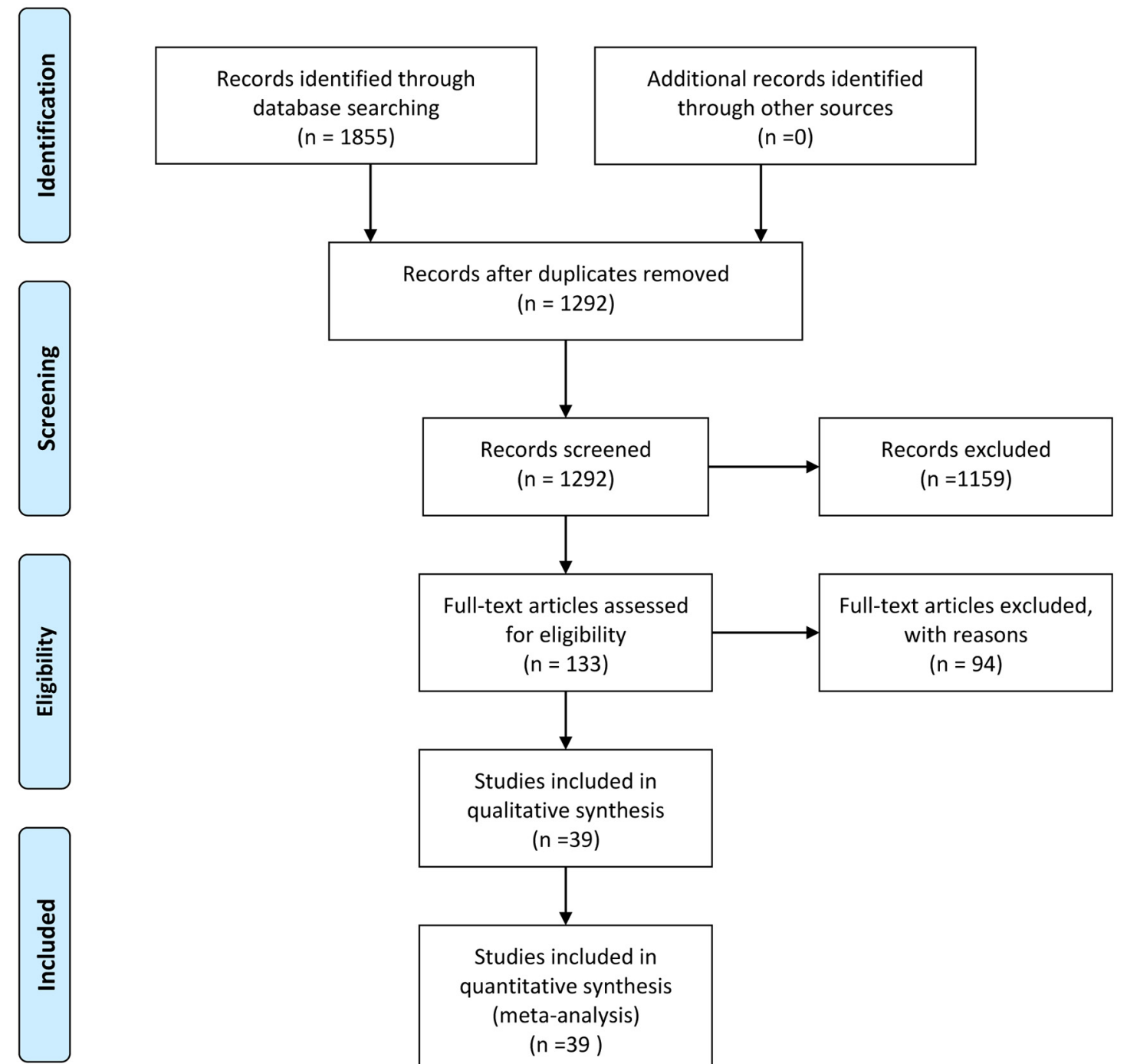

Studies included in qualitative synthesis $(n=39)$

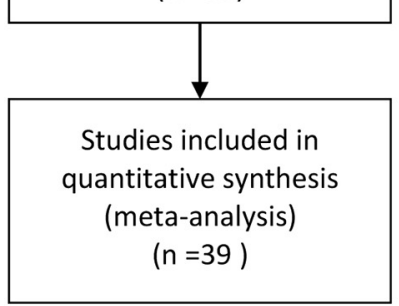

Fig 1. Flow diagram of the study selection process. From: Moher D, Liberati A, Tetzlaff J, Altman DG, The PRISMA Group (2009). Preferred Reporting /terns for Systematic Reviews and Meta-Analyses: The PRISMA Statement. PLoS Med 6(6): e1000097. doi:10.1371/journal.pmed1000097 For more information, visit www. prisma-statement.org.

doi:10.1371/journal.pone.0153454.g001

Additionally, the prevalence of depression among university students from South China (27.5\%, 95\% CI: 20.5\%-36.7\%) was higher than among students from North China (21.3\%, 95\%CI: $16.8 \%-27.0 \%)$. Regarding the prevalence of depression according to sample size, the pooled prevalence for sample sizes $<500,500-1000$ and $>1000$ were $19.8 \%$ (95\% CI: $13.4 \%-$ 29.3\%), 25.4\% (95\% CI: 19.2\%-33.6\%), and 25.0\% (95\% CI: 17.9\%-34.9\%), respectively.

Besides, no significant difference was observed between studies that have used self-reported 
Table 1. Characteristics of Studies on the Prevalence of Depression among Chinese College Students.

\begin{tabular}{|c|c|c|c|c|c|c|c|c|c|c|c|}
\hline \multirow{2}{*}{$\begin{array}{c}\text { Authors and } \\
\text { published years }\end{array}$} & \multirow[t]{2}{*}{ Province } & \multirow[t]{2}{*}{ Area } & \multirow{2}{*}{$\begin{array}{c}\text { Sample } \\
\text { size } \\
\text { (case/total) }\end{array}$} & \multirow[t]{2}{*}{ Age } & \multirow{2}{*}{$\begin{array}{c}\text { Male } \\
\text { percent } \\
(\%)\end{array}$} & \multicolumn{3}{|c|}{ Prevalence } & \multirow{2}{*}{$\begin{array}{l}\text { Medical } \\
\text { student }\end{array}$} & \multirow{2}{*}{ Grade } & \multirow{2}{*}{$\begin{array}{c}\text { Screening } \\
\text { methods }\end{array}$} \\
\hline & & & & & & $\begin{array}{l}\text { Total } \\
(\%)\end{array}$ & $\begin{array}{l}\text { Male } \\
(\%)\end{array}$ & $\begin{array}{c}\text { Female } \\
(\%)\end{array}$ & & & \\
\hline Liu.et al.1997 & Shandong & Northern & $97 / 560$ & $\begin{array}{c}\text { Mean(SD) } 20.85 \\
(1.81)\end{array}$ & 57.5 & 17.3 & 18.94 & 15.13 & Yes & $1-4$ & SDS \\
\hline Du.et al.1999 & Shandong & Northern & $706 / 1597$ & $\begin{array}{c}\text { Mean(SD) } 20.56 \\
(1.40)\end{array}$ & 60.6 & 44.2 & NA & NA & Yes & NA & $\mathrm{BDI}$ \\
\hline Xu.et al.2002 & Liaoning & Northern & $31 / 211$ & $\begin{array}{c}\text { Mean(range) } 19.7 \\
(17-21)\end{array}$ & 38.9 & 14.7 & 17.08 & 13.18 & Yes & 1 & SDS \\
\hline Xu.et al.2003 & Hebei & Northern & $381 / 1750$ & Mean 21.8 & 48.3 & 21.8 & NA & NA & No & NA & SDS \\
\hline Zeng.et al.2003 & Guangdong & Southern & $40 / 302$ & $\begin{array}{c}\text { Mean(SD) } 21.08 \\
(1.12)\end{array}$ & 70.9 & 13.3 & NA & NA & No & $1-4$ & SDS \\
\hline Zhou.et al.2003 & Guangdong & Southern & $71 / 176$ & $\begin{array}{c}\text { Mean(SD) } 21.43 \\
(0.85)\end{array}$ & 47.8 & 40.3 & 35.23 & 45.45 & Yes & NA & SDS \\
\hline Qu.et al.2005 & Liaoning & Northern & $114 / 509$ & $\begin{array}{c}\text { Mean(SD) } 20.79 \\
(1.28)\end{array}$ & 41.1 & 22.4 & 25.36 & 20.33 & Yes & $1-4$ & SDS \\
\hline Zhang.et al.2005 & Henan & Southern & $615 / 1351$ & $\begin{array}{c}\text { Mean(SD) } 20.0 \\
(1.0)\end{array}$ & 42.7 & 45.5 & 44.73 & 45.74 & No & $1-3$ & SDS \\
\hline Mei.et al.2006 & Beijing & Southern & $77 / 526$ & $\begin{array}{c}\text { Mean(range) } 22 \\
(20-23)\end{array}$ & 51.1 & 14.6 & NA & NA & Yes & 4 & SDS \\
\hline Xiao.et al.2006 & Hubei & Southern & $218 / 558$ & Range 16-25 & 44.3 & 39.1 & 44.90 & 34.40 & No & NA & SDS \\
\hline Zeng.et al.2006 & Hunan & Southern & $205 / 408$ & Range 17-25 & 55.4 & 50.2 & 50.00 & 50.54 & Yes & $1-5$ & SDS \\
\hline Zhang.et al.2006 & Guangdong & Southern & $693 / 860$ & $\begin{array}{c}\text { Mean(SD) } 21.5 \\
(2.3)\end{array}$ & 47.4 & 80.6 & 84.6 & 77.0 & Yes & $1-4$ & DSI \\
\hline Shi.et al.2006 & Shanxi & Northern & $48 / 658$ & $\begin{array}{c}\text { Mean(range) } 21.5 \\
(17-27)\end{array}$ & 45.0 & 7.3 & NA & NA & No & $1-5$ & SDS, HAMD \\
\hline Wang.et al.2007 & Chongqing & Southern & $396 / 1440$ & $\begin{array}{c}\text { Mean(SD) } 20.82 \\
(2.27)\end{array}$ & 56.3 & 27.5 & NA & NA & Yes & NA & SDS \\
\hline Yang.et al.2007 & Jiangsu & Southern & $113 / 3744$ & Range 16-23 & 75.5 & 3.0 & 3.29 & 2.18 & No & NA & SDS \\
\hline Zou.et al.2007 & Shandong & Northern & $73 / 434$ & $\begin{array}{c}\text { Mean(SD) } 19.97 \\
(1.15)\end{array}$ & 45.4 & 16.8 & NA & NA & No & NA & SDS \\
\hline Zheng.et al.2008 & Henan & Northern & $784 / 1274$ & $\begin{array}{c}\text { Mean(SD) } 19.14 \\
(1.34)\end{array}$ & 25.9 & 61.5 & NA & NA & No & $1-3$ & SDS \\
\hline Chen.et al.2009 & Guangdong & Southern & $381 / 719$ & NA & NA & 53.0 & NA & NA & No & NA & SDS \\
\hline Yao.et al.2009 & Hunan & Southern & $157 / 640$ & $\begin{array}{c}\text { Mean(SD) } 20.1 \\
(1.1)\end{array}$ & 46.4 & 24.6 & NA & NA & No & $2-3$ & DEQ \\
\hline Fu.et al.2010 & Jilin & Northern & $321 / 631$ & NA & 51.7 & 50.9 & NA & NA & No & NA & SDS \\
\hline Niu.et al.2010 & Shandong & Northern & $132 / 609$ & NA & 52.9 & 21.7 & 23.91 & 19.16 & No & 1 & SDS \\
\hline Xi.et al.2010 & Hebei & Northern & $84 / 402$ & NA & NA & 20.9 & NA & NA & No & NA & SDS \\
\hline Zhong.et al.2010 & Beijing & Northern & $56 / 266$ & $\begin{array}{c}\text { Mean(SD) } 18.49 \\
(0.79)\end{array}$ & 54.7 & 21.1 & 14.49 & 21.85 & No & NA & $\mathrm{BDI}$ \\
\hline Chai.et al.2011 & Hubei & Southern & $400 / 1681$ & Range 18-22 & 53.5 & 23.8 & 23.11 & 24.58 & No & $1-3$ & SDS \\
\hline Hao.et al.2011 & Shanxi & Northern & $214 / 562$ & Range 17-25 & 44.1 & 38.1 & 44.00 & 33.40 & No & $1-4$ & SDS \\
\hline Liu.et al.2011 & Shandong & Northern & $54 / 185$ & Range 17-20 & 48.2 & 29.2 & NA & NA & No & 1 & SDS \\
\hline Wei.et al.2011 & Fujian & Southern & $151 / 391$ & $\begin{array}{c}\text { Mean(SD) } 20.0 \\
(2.0)\end{array}$ & 42.2 & 38.6 & NA & NA & No & $1-4$ & SDS \\
\hline Yu.et al.2011 & Shanxi & Northern & $140 / 600$ & $\begin{array}{c}\text { Mean(SD) } 20.25 \\
(1.15)\end{array}$ & 12.5 & 23.3 & 28.00 & 22.67 & No & $1-3$ & SDS \\
\hline $\begin{array}{c}\text { Zhong.et al. } \\
2011\end{array}$ & Beijing & Northern & $290 / 742$ & $\begin{array}{c}\text { Mean(SD) } 20.73 \\
(1.58)\end{array}$ & 68.6 & 39.1 & 43.02 & 30.47 & No & $1-4$ & HAMD \\
\hline Du.et al.2013 & Heilongjiang & Northern & $45 / 650$ & $\begin{array}{l}\text { Mean(range) } 21 \\
(19-25)\end{array}$ & 66.2 & 6.9 & NA & NA & No & NA & SDS, HAMD \\
\hline
\end{tabular}


Table 1. (Continued)

\begin{tabular}{|c|c|c|c|c|c|c|c|c|c|c|c|}
\hline \multirow{2}{*}{$\begin{array}{l}\text { Authors and } \\
\text { published years }\end{array}$} & \multirow[t]{2}{*}{ Province } & \multirow[t]{2}{*}{ Area } & \multirow{2}{*}{$\begin{array}{c}\text { Sample } \\
\text { size } \\
\text { (case/total) }\end{array}$} & \multirow[t]{2}{*}{ Age } & \multirow{2}{*}{$\begin{array}{c}\text { Male } \\
\text { percent } \\
(\%)\end{array}$} & \multicolumn{3}{|c|}{ Prevalence } & \multirow{2}{*}{$\begin{array}{l}\text { Medical } \\
\text { student }\end{array}$} & \multirow{2}{*}{ Grade } & \multirow{2}{*}{$\begin{array}{l}\text { Screening } \\
\text { methods }\end{array}$} \\
\hline & & & & & & $\begin{array}{c}\text { Total } \\
(\%)\end{array}$ & $\begin{array}{c}\text { Male } \\
(\%)\end{array}$ & $\begin{array}{c}\text { Female } \\
(\%)\end{array}$ & & & \\
\hline Chen.et al.2013 & Heilongjiang & Northern & $19 / 477$ & Range 16-25 & 48.9 & 4.0 & NA & NA & No & $1-5$ & BDI \\
\hline Sun.et al.2013 & Hebei & Northern & $510 / 690$ & $\begin{array}{c}\text { Mean(SD) } 21.0 \\
(2.0)\end{array}$ & 80.9 & 73.9 & 74.2 & 72.8 & No & $1-4$ & CES-D \\
\hline Meng.et al.2013 & Hubei & Southern & $319 / 1145$ & $\begin{array}{c}\text { Mean(SD) } 21.61 \\
(1.66)\end{array}$ & 38.7 & 27.9 & NA & NA & No & $1-4$ & SCL-90-R \\
\hline Zhang.et al.2013 & Henan & Northern & $84 / 959$ & $\begin{array}{c}\text { Mean(SD) } 21.45 \\
(1.04)\end{array}$ & 45.7 & 8.8 & NA & NA & Yes & NA & BDI \\
\hline Liu.et al.2014 & Hunan & Southern & 201/804 & Range 17-24 & 45.1 & 25.0 & 26.45 & 23.81 & No & $1-3$ & CES-D \\
\hline Feng.et al.2014 & Hubei & Southern & $117 / 1106$ & $\begin{array}{c}\text { Mean(SD) } 18.90 \\
(0.98)\end{array}$ & 57.4 & 10.6 & NA & NA & No & 1 & SDS \\
\hline Han.et al.2015 & Liaoning & Northern & $70 / 843$ & NA & 29.5 & 8.3 & NA & NA & Yes & NA & SDS \\
\hline Hong.et al.2015 & Beijing & Northern & $398 / 1186$ & Range 15-25 & 35.3 & 33.6 & 34.6 & 34.0 & No & $1-4$ & SDS \\
\hline Lu.et al.2015 & Shanghai & Southern & $687 / 1048$ & $\begin{array}{c}\text { Mean(SD) } 18.63 \\
(0.84)\end{array}$ & 66.3 & 65.6 & 65.5 & 65.7 & No & 1 & $\begin{array}{c}\text { Chinese version of } \\
\text { PHQ-9 }\end{array}$ \\
\hline
\end{tabular}

Abbreviations: BDI = Beck Depression Inventory; CES-D = Center for Epidemiological Survey, Depression Scale DEQ = Depressive Experiences Questionnaire; DSI = Depression Status Inventory; SDS = the Self-rating Depression Scale; HAMD = Hamilton Depression Scale; NA = Not available; $\mathrm{PHQ}=$ Patient Health Questionnaire; SCL-90-R = the revised Hopkins' Symptom checklist

doi:10.1371/journal.pone.0153454.t001

depression instruments (24.0\%, 95\% CI: 19.4\%-29.7\%) and those that have used a clinicianrated instrument $(23.7 \%$, 95\% CI: $18.0 \%-31.1 \%)$.

\section{Sensitivity analysis}

To examine the stability of the pooled prevalence of depression, each study was sequentially excluded. And the results of sensitivity analysis demonstrated that none of the exclusions of any specific study evidently altered our results, which revealed that the prevalence of depression among Chinese university students is exceedingly high (Fig 3).

\section{Publication bias}

The publication bias of each study was first assessed using Begg's funnel plot. Strong evidence of asymmetry was revealed by the shape of the funnel plot, suggesting the presence of publication bias. Then, the trim and fill method was applied to further quantitatively assess publication bias by filling the funnel plot using the random-effects model, estimating six potential studies were missing (Fig 4). The recalculated overall prevalence of depression according to the trim and fill method was $19.5 \%$ (95\% CI: $13.8 \%-27.7 \%)$. Overall, it is likely that publication bias exists among the included studies according to the above statistical results.

\section{Discussion}

This meta-analysis of 39 epidemiological studies is the first systematic report summarizing the prevalence estimations of depression in Chinese university students. This comprehensive meta-analysis of observational studies conducted in China during the last 20 years included more than 30,000 university students. This meta-analysis is likely to provide a trustworthy estimate of the prevalence of depression among Chinese university students. The results of this 


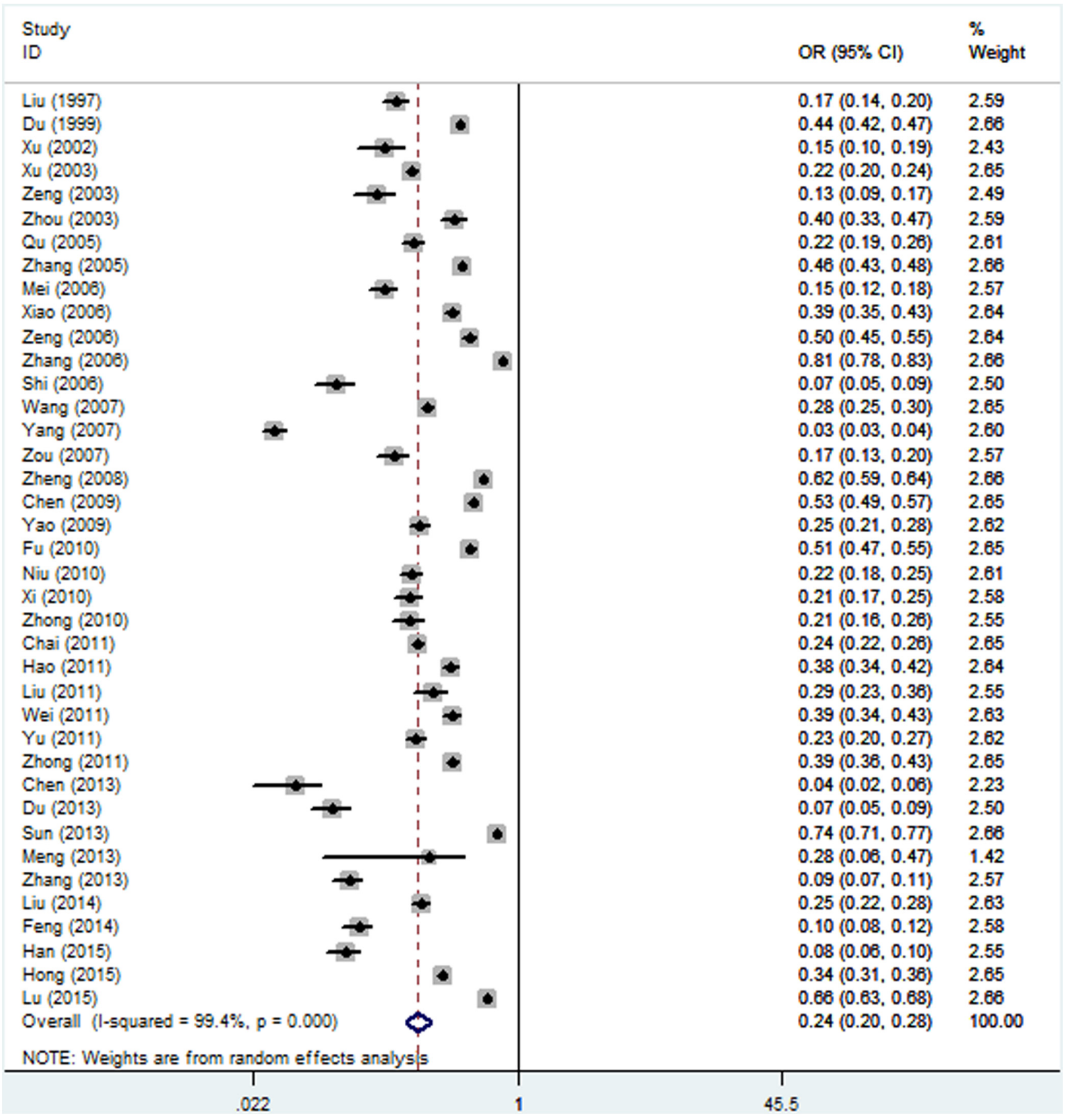

Fig 2. Forest plot of the prevalence of depression for the total population.

doi:10.1371/journal.pone.0153454.g002

meta-analysis indicate that the prevalence of depression among Chinese university students is $23.8 \%$ (95\% CI: $19.9 \%-28.5 \%$ ), which is close to earlier reported estimates and falls within the range of $10 \%-85 \%$ that was reported in another systematic review of depression in university students worldwide, but the prevalence is relatively lower than estimates of the global prevalence of depression (weighted mean prevalence: 30.6\%) [14]. 
Table 2. Subgroup Analysis of Depression among Chinese College Students According to Different Categories.

\begin{tabular}{|c|c|c|c|c|c|c|c|c|}
\hline \multirow[t]{2}{*}{ Category } & \multirow[t]{2}{*}{ Subgroup } & \multirow[t]{2}{*}{ NO. of studies } & \multirow[t]{2}{*}{ Prevalence $(95 \% \mathrm{Cl})(\%)$} & \multirow[t]{2}{*}{$\mathbf{N}$} & \multirow[t]{2}{*}{$\mathrm{I}^{2}(\%)$} & \multirow[t]{2}{*}{$\mathbf{P}$} & \multicolumn{2}{|c|}{ Publication Bias Tests } \\
\hline & & & & & & & P (Begg's Test) & P (Egger's Test) \\
\hline & Total & 39 & $23.8(19.9-28.5)$ & 32694 & 99.4 & $<0.001$ & 0.894 & 0.001 \\
\hline \multirow[t]{4}{*}{ Study year } & 1995-2000 & 2 & $27.8(11.1-69.6)$ & 2157 & 98.9 & $<0.001$ & 1.000 & 0.001 \\
\hline & 2001-2005 & 6 & $24.0(16.1-35.8)$ & 4299 & 98.2 & $<0.001$ & 1.000 & 0.855 \\
\hline & 2006-2010 & 15 & $25.2(18.2-34.7)$ & 13169 & 99.5 & $<0.001$ & 0.882 & 0.001 \\
\hline & 2011-2015 & 16 & $21.9(16.2-29.6)$ & 13069 & 99.3 & $<0.001$ & 0.241 & 0.032 \\
\hline \multirow[t]{2}{*}{ Sex } & Male & 19 & $30.0(14.9-60.2)$ & 9430 & 99.9 & $<0.001$ & 0.033 & 0.001 \\
\hline & Female & 19 & $27.1(13.2-55.5)$ & 7559 & 99.9 & $<0.001$ & 0.220 & 0.001 \\
\hline \multirow[t]{2}{*}{ Male percent } & $<50 \%$ & 21 & $24.1(18.6-31.2)$ & 15573 & 99.3 & $<0.001$ & 0.833 & 0.047 \\
\hline & $\geq 50 \%$ & 16 & $22.3(16.4-30.2)$ & 16000 & 99.5 & $<0.001$ & 0.652 & 0.001 \\
\hline \multirow[t]{2}{*}{ Medical students } & Yes & 11 & 27.5 (19.8-38.3) & 9054 & 99.4 & $<0.001$ & 0.640 & 0.169 \\
\hline & No & 28 & $22.4(17.9-28.1)$ & 23660 & 99.3 & $<0.001$ & 0.707 & 0.001 \\
\hline \multirow[t]{2}{*}{ Area } & Northern & 22 & $21.3(16.8-27.0)$ & 15795 & 99.1 & $<0.001$ & 0.352 & 0.006 \\
\hline & Southern & 17 & $27.5(20.5-36.7)$ & 16899 & 99.5 & $<0.001$ & 0.117 & 0.001 \\
\hline \multirow[t]{3}{*}{ Sample size } & $<500$ & 10 & $19.8(13.4-29.3)$ & 3425 & 97.7 & $<0.001$ & 0.025 & 0.001 \\
\hline & $500-1000$ & 18 & 25.4(19.2-33.6) & 11947 & 99.4 & $<0.001$ & 0.023 & 0.002 \\
\hline & $>1000$ & 11 & $25.0(17.9-34.9)$ & 17322 & 99.5 & $<0.001$ & 0.696 & 0.001 \\
\hline \multirow[t]{2}{*}{ Screening method } & Self-report & 26 & $24.0(19.4-29.7)$ & 22158 & 99.1 & $<0.001$ & 0.415 & 0.001 \\
\hline & Clinical instrument & 13 & $23.7(18.0-31.1)$ & 10536 & 99.4 & $<0.001$ & 0.300 & 0.090 \\
\hline
\end{tabular}

doi:10.1371/journal.pone.0153454.t002

Negative life events may play a significant role in the development of depression. Compared to non-depressed university students, students with depressive symptoms often reported experiencing more negative events [28]. More so, university students with depressive symptoms also stated that negative life events had a great impact on their lives, suggesting that they not only experienced a high frequency of negative life events but also felt a great degree of stress resulting from these negative life events [43]. Findings also suggested that negative life events, such as failure in love, separation of parents and financial deficits, were direct source of stimulation inducing depression. University students with more negative life experiences are at increased risk for developing depression [44].

Some studies have found higher levels of depression among female students than male students $[12,45]$. However, we found no significant difference in the prevalence of depression between female and male sexes in the current study. Similarly, previous studies have observed no differences in depressive symptoms between male and female students $[6,10]$. This could be explained by the fact that female students in Chinese universities enjoy equal political rights, experience the same pressures as male students, and have same job opportunities as their male peers [30].

Our study revealed that the prevalence of depression among medical students was higher compared to other students. Several theories explaining this trend have been presented in many studies. Some have attributed this result to the fact that medical students go through continuous examinations throughout their academic study. Studying medicine is relatively more competitive compared to other majors of study, and several unique academic stressors have been reported in various previous studies [12]. Students in other disciplines undergo fewer examinations and easier courses of study compared to medical students. Others have stated that medical students are more likely to be critical of themselves. Anecdotal evidence suggests that medical students tend to be more socially isolated than other students. Besides, medical 


\section{Meta-analysis random-effects estimates (exponential form) Study ommited}

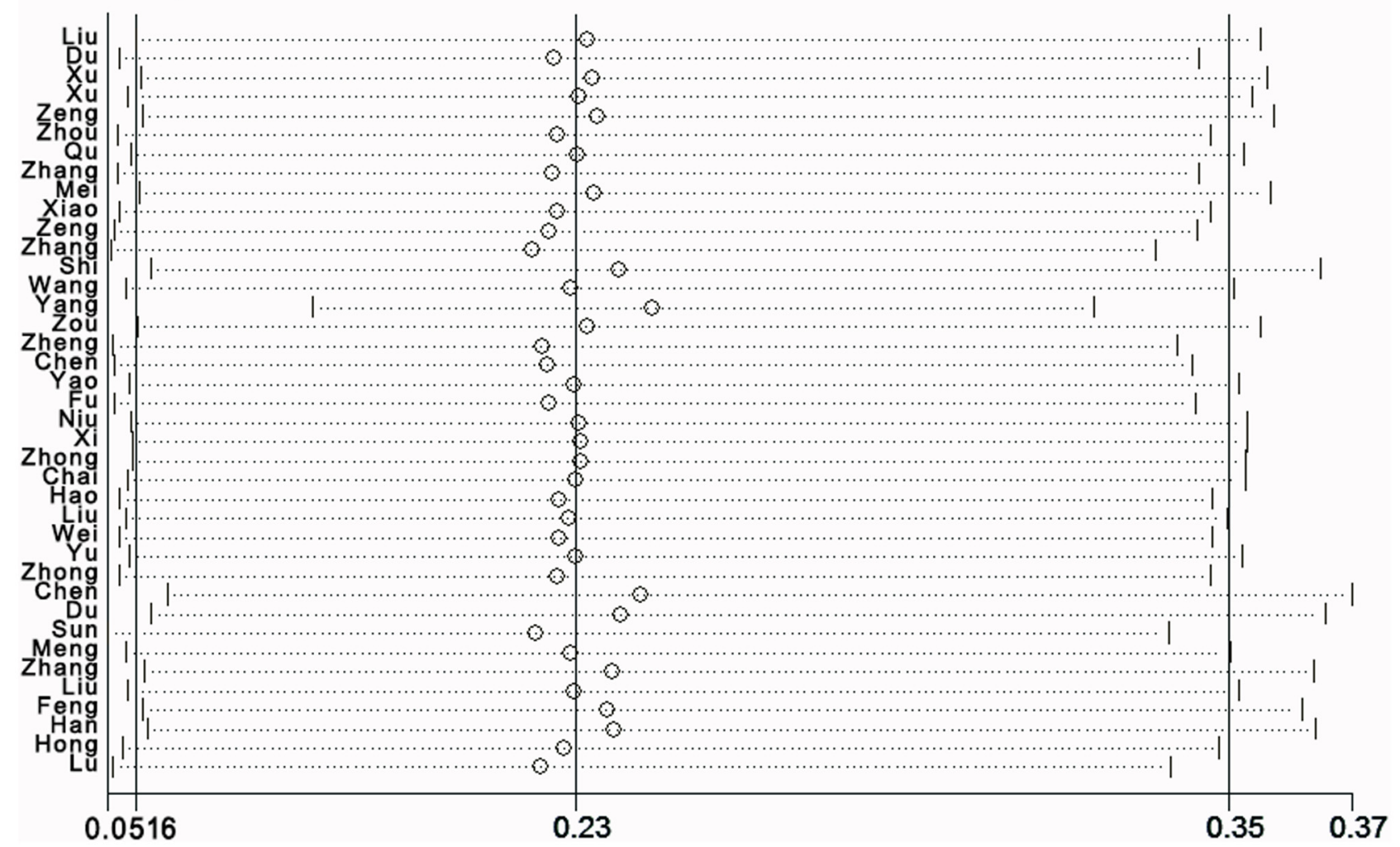

Fig 3. Plot of sensitivity analysis by excluding one study each time and the pooling estimate for the rest of the studies.

doi:10.1371/journal.pone.0153454.g003

education may inevitably have negative effects on mental health and increase the risk of depression among medical students $[14,46]$. The cumulative impact of these various factors may explain why medical students experience higher rates of depression compared to students in other disciplines.

Subgroup analysis also revealed that the prevalence of depression in southern areas of China was higher compared to than in northern areas of the country. Similar results have not been found in previous studies, as nationwide investigation on this topic is scarce. This variance could be explained by differences in education, family income, medical insurance, and other social-culture factors between southern and northern part of China. However, further research is required to confirm the difference in the prevalence of depression between southern and northern areas of China and to evaluate the factors that might lead to such differences. This may be useful in the development of primary prevention strategies.

Even though this meta-analysis included 39 studies and encompassed a larger sample size than any individual study, some limitations deserve to be acknowledged and discussed. First, substantial heterogeneity was observed in both the overall analysis and subgroups analyses. Some of the selected studies had limited sample sizes that produced imprecise estimates. And part of the heterogeneity across various studies could be explained by the diverse sample sizes and sex ratios. In addition, the differences in screening methods among the various studies may have contributed to the observed heterogeneity. Some factors that may have contributed to the heterogeneity must be acknowledged. 


\section{Filled funnel plot with pseudo $95 \%$ confidence limits}

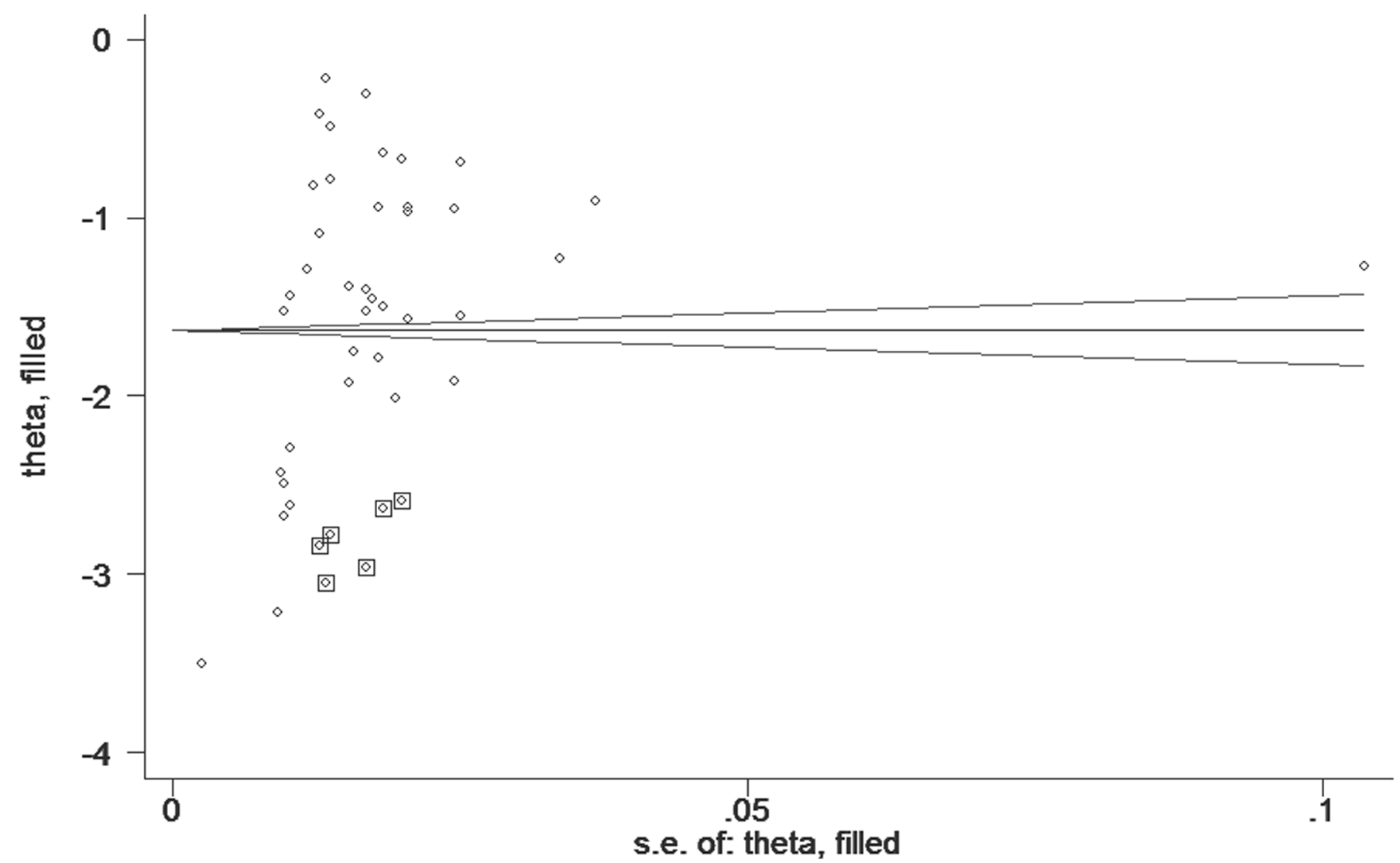

Fig 4. Filled funnel plot of the included studies (log odds ratio, horizontal axis; standard error, vertical axis).

A second possible limitation of this study is related to publication bias. Although the results from Egger's test and Begg's test were inconsistent, there was evidence of publication bias, mostly from language bias resulted from unbalanced number of studies published in different languages (32 in Chinese and 7 in English) and the inflated estimates resulted from limited methodological design in some studies, The included studies had noted methodological flaws, especially related to selection and recruitment of university students with depression. The samples of students participating in the investigations may not be representative of other student samples in China. This may have led to subjects being included in studies who differed in important ways from those who were excluded or ineligible for statistical analyses. As a result, the estimates of prevalence may have been influenced in unpredictable ways [21].

In conclusion, the prevalence of depression among Chinese university students is high, mostly resulted from the expanded social interactions and changing situations in residence and finance. Future studies in this field should be more focused on the characteristics of the participants to find key factors that contribute to the prevalence. In consideration of the new policies that aim to expand enrollment at universities in China are being implemented, we hope this meta-analysis that summarizes research over the past 20 years will serve as an alarm bell to the university administration. The results of our study should stimulate not only more research on university students as a distinct group, but also encourage families, universities, and society as 
a whole to develop and implement strategies to help the young to overcome their difficulties and lead a healthier life.

\section{Supporting Information}

S1 Table. PRISMA 2009 Checklist.

(DOC)

S1 Text. References from 32 Chinese studies that were included in the meta-analysis. (DOCX)

\section{Acknowledgments}

We thank Dr. Wei Liu for her careful work in revising the manuscript.

\section{Author Contributions}

Conceived and designed the experiments: YML XYL. Performed the experiments: LMX YNL. Analyzed the data: LMX YNL. Contributed reagents/materials/analysis tools: XYL. Wrote the paper: XYL YML.

\section{References}

1. Kessler RC, Berglund P, Demler O, Jin R, Koretz D, Merikangas KR, et al. The epidemiology of major depressive disorder: results from the National Comorbidity Survey Replication (NCS-R). Jama. 2003; 289: 3095-3105. PMID: 12813115

2. Hysenbegasi A, Hass SL and Rowland CR. The impact of depression on the academic productivity of university students. Journal of Mental Health Policy and Economics. 2005; 8: 145. PMID: 16278502

3. Hu T-w. The economic burden of depression and reimbursement policy in the Asia Pacific region. Australasian Psychiatry. 2004; 12: s11-s15. PMID: 15715825

4. Sobocki $\mathrm{P}$, Lekander I, Borgström F, Ström $\mathrm{O}$ and Runeson $\mathrm{B}$. The economic burden of depression in Sweden from 1997 to 2005. European Psychiatry. 2007; 22: 146-152. PMID: 17194573

5. Steptoe A, Tsuda A and Tanaka Y. Depressive symptoms, socio-economic background, sense of control, and cultural factors in university students from 23 countries. International journal of behavioral medicine. 2007; 14: 97-107. PMID: 17926438

6. Bayram $\mathrm{N}$ and Bilgel $\mathrm{N}$. The prevalence and socio-demographic correlations of depression, anxiety and stress among a group of university students. Social psychiatry and psychiatric epidemiology. 2008; 43: 667-672. doi: 10.1007/s00127-008-0345-x PMID: 18398558

7. Voelker R. Mounting student depression taxing campus mental health services. Jama. 2003; 289: 2055-2056. PMID: 12709447

8. Amarasuriya SD, Jorm AF and Reavley NJ. Prevalence of depression and its correlates among undergraduates in Sri Lanka. Asian journal of psychiatry. 2015; 15: 32-37 doi: 10.1016/j.ajp.2015.04.012 PMID: 25998095

9. Ibrahim MB and Abdelreheem MH. Prevalence of anxiety and depression among medical and pharmaceutical students in Alexandria University. Alexandria Journal of Medicine. 2015; 51: 167-173

10. Bostanci M, Ozdel O, Oguzhanoglu NK, Ozdel L, Ergin A, Ergin N, et al. Depressive symptomatology among university students in Denizli, Turkey: prevalence and sociodemographic correlates. Croat Med J. 2005; 46: 96-100. PMID: 15726682

11. Eller T, Aluoja A, Vasar V and Veldi M. Symptoms of anxiety and depression in Estonian medical students with sleep problems. Depression and anxiety. 2006; 23: 250. PMID: 16555263

12. Mikolajczyk RT, Maxwell AE, El Ansari W, Naydenova V, Stock C, llieva S, et al. Prevalence of depressive symptoms in university students from Germany, Denmark, Poland and Bulgaria. Social psychiatry and psychiatric epidemiology. 2008; 43: 105-112. PMID: 18038173

13. Ovuga E, Boardman J and Wasserman D. Undergraduate student mental health at Makerere University, Uganda. World Psychiatry. 2006; 5: 51. PMID: 16757997 
14. Ibrahim AK, Kelly SJ, Adams CE and Glazebrook C. A systematic review of studies of depression prevalence in university students. Journal of psychiatric research. 2013; 47: 391-400. doi: 10.1016/j. jpsychires.2012.11.015 PMID: 23260171

15. Garlow SJ, Rosenberg J, Moore JD, Haas AP, Koestner B, Hendin H, et al. Depression, desperation, and suicidal ideation in college students: results from the American Foundation for Suicide Prevention College Screening Project at Emory University. Depression and anxiety. 2008; 25: 482-488. PMID: 17559087

16. Kisch J, Leino EV and Silverman MM. Aspects of suicidal behavior, depression, and treatment in college students: Results from the Spring 2000 National College Health Assessment Survey. Suicide and Life-Threatening Behavior. 2005; 35: 3-13. PMID: 15843320

17. Mushquash AR, Stewart SH, Sherry SB, Sherry DL, Mushquash CJ and MacKinnon AL. Depressive symptoms are a vulnerability factor for heavy episodic drinking: A short-term, four-wave longitudinal study of undergraduate women. Addictive behaviors. 2013; 38: 2180-2186. doi: 10.1016/j.addbeh. 2012.11.008 PMID: 23454875

18. Buckner JD, Keough ME and Schmidt NB. Problematic alcohol and cannabis use among young adults: The roles of depression and discomfort and distress tolerance. Addictive behaviors. 2007; 32: 1957-1963. PMID: 17258398

19. Adams TB, Wharton $C M$, Quilter $L$ and Hirsch $T$. The association between mental health and acute infectious illness among a national sample of 18-to 24-year-old college students. Journal of American College Health. 2008; 56: 657-664. doi: 10.3200/JACH.56.6.657-664 PMID: 18477521

20. Luo MY. Social Assessment and Subdividing of After-1980s. China Youth Study.2010; 11: 32-35.

21. Li Z-Z, Li Y-M, Lei X-Y, Zhang D, Liu L, Tang SY, et al. Prevalence of Suicidal Ideation in Chinese College Students: A Meta-Analysis. PLoS ONE. 2014; 9(10): e104368. doi: 10.1371/journal.pone. 0104368 PMID: 25285890

22. Yen S, Robins C J, Lin N. A cross-cultural comparison of depressive symptom manifestation: China and the United States. Journal of consulting and clinical psychology. 2000; 68(6): 993. PMID: 11142551

23. Stuart A and Ord JK. Kendall's Advanced Theory of Statistics, Volume I: Distribution Theory. Arnold London; 1994.

24. DerSimonian R and Laird N. Meta-analysis in clinical trials. Controlled clinical trials. 1986; 7: 177-188. PMID: 3802833

25. Higgins JP, Thompson SG, Deeks JJ and Altman DG. Measuring inconsistency in meta-analyses. BMJ: British Medical Journal. 2003; 327: 557. PMID: 12958120

26. Deeks JJ, Altman DG and Bradburn MJ. Statistical methods for examining heterogeneity and combining results from several studies in meta-analysis. Systematic Reviews in Health Care: Meta-Analysis in Context, Second Edition; 2008. pp. 285-312.

27. Egger M, Smith GD, Schneider $M$ and Minder $C$. Bias in meta-analysis detected by a simple, graphical test. BMJ (Clinical research ed). 1997; 315: 629-634.

28. Zong J-G, Cao X-Y, Cao Y, Shi Y-F, Wang Y-N, Yan C, et al. Research Coping flexibility in college students with depressive symptoms. Health and Quality of Life Outcomes. 2010; 8: 66

29. Yao S, Fang J, Zhu X and Zuroff DC. The Depressive Experiences Questionnaire: construct validity and prediction of depressive symptoms in a sample of Chinese undergraduates. Depression and anxiety. 2009; 26: 930-937. doi: 10.1002/da.20465 PMID: 19067317

30. Chen L, Wang L, Qiu XH, Yang XX, Qiao ZX, Yang YJ, et al. Depression among Chinese university students: prevalence and socio-demographic correlates. PLoS ONE. 2013; 8(3): e58379. doi: 10.1371/ journal.pone.0058379 PMID: 23516468

31. Meng H, Li J, Loerbroks A, Wu J and Chen H. Rural/urban background, depression and suicidal ideation in Chinese college students: a cross-sectional study. PloS ONE. 2013; 8: e71313. doi: 10.1371/ journal.pone.0071313 PMID: 23977015

32. Zhang YL, Liang W, Chen ZM, Zhang HM, Zhang JH, Weng XQ, et al. Validity and reliability of Patient Health Questionnaire-9 and Patient Health Questionnaire-2 to screen for depression among college students in China. Asia-Pacific Psychiatry. 2013; 5: 268-275. doi: 10.1111/appy.12103 PMID: 24123859

33. Feng Q, Du Y, Ye Y-I and He Q-q. Associations of physical activity, screen time with depression, anxiety and sleep quality among Chinese college freshmen. PLoS ONE. 2014; 9(6): e100914. doi: 10. 1371/journal.pone.0100914 PMID: 24964250

34. Lu W, Bian Q, Song Y Y, Ren JY, Xun XY and Zhao M. Prevalence and related risk factors of anxiety and depression among Chinese college freshmen. Journal of Huazhong University of Science and Technology [Medical Sciences]. 2015; 35: 815-822. 
35. Zung W W K. A self-rating depression scale. Archives of general psychiatry. 1965; 12(1): 63-70.

36. Beck A T, Ward C, Mendelson M. Beck depression inventory (BDI). Arch Gen Psychiatry. 1961; 4(6): 561-571.

37. Zung W W K. Zung self-rating depression scale and depression status inventory. Assessment of depression. Springer Berlin Heidelberg; 1986. pp. 221-231.

38. Faries D, Herrera J, Rayamajhi J, DeBrota D, Demitrack M and Potter WZ. The responsiveness of the Hamilton depression rating scale. Journal of psychiatric research. 2000; 34(1): 3-10. PMID: 10696827

39. Bagby R M, Parker J D A, Joffe R T and Buis T. Reconstruction and validation of the Depressive Experiences Questionnaire. Assessment. 1994; 1(1): 59-68. PMID: 9463501

40. Radloff $L S$. The CES-D scale a self-report depression scale for research in the general population. Applied psychological measurement. 1977; 1(3): 385-401.

41. Löwe B, Kroenke K, Herzog W and Gräfe K. Measuring depression outcome with a brief self-report instrument: sensitivity to change of the Patient Health Questionnaire (PHQ-9). Journal of affective disorders. 2004; 81(1): 61-66. PMID: 15183601

42. Derogatis L R and Unger R. Symptom checklist-90-revised. Corsini encyclopedia of psychology; 2010.

43. Brown GW and Harris T. Social origins of depression: A study of psychiatric disorder in women. Routledge; 2012.

44. Wu J, Wu YT, Feng SX, Meng $\mathrm{H}$, Chen $\mathrm{H}$. Mediating effects on depression regarding the relationship between negative life events and suicide ideation among college students. Chin J Epidem. 2012; 33:1111-1115.

45. Franko DL, Striegel-Moore RH, Bean J, Barton BA, Biro F, Kraemer HC, et al. Self-reported symptoms of depression in late adolescence to early adulthood: a comparison of African-American and Caucasian females. Journal of Adolescent Health. 2005; 37: 526-529. PMID: 16310134

46. Nguyen $\mathrm{M}$. Why medical school is depressing and what we should be doing about it. Australian Medical Student Journal. 2011; 2(1): 65-8. 